\title{
Conformational analysis of menthol diastereomers by NMR and DFT computation
}

\author{
Julia Härtner, Uwe M. Reinscheid * \\ Max Planck Institute for Biophysical Chemistry, NMR II, Am Fassberg 11, 37077 Göttingen, Germany
}

Received 19 October 2006; received in revised form 21 February 2007; accepted 21 February 2007

Available online 28 February 2007

\begin{abstract}
Correlations between experimental and calculated ${ }^{13} \mathrm{C}$ chemical shifts were performed with the series of all menthol diastereomers. In this way it could be shown that identification problems with newly isolated natural products can be solved. Starting from simulated, low energy conformers of menthol, neomenthol, isomenthol, and neoisomenthol the ${ }^{13} \mathrm{C}$ chemical shifts were obtained using DFT calculations [functional: B3LYP, basis set: 6-31G(d,p)]. Due to differences in chemical shifts, the prochiral methyl groups of the isopropyl substituent of menthol could be differentiated using the correlations between experimental and calculated values. A conformational scan of the dihedral angle of the isopropyl group allowed the determination of the dominating rotamers of menthol $\left(+68.4^{\circ}\right)$ and neomenthol $\left(+172.5^{\circ}\right)$ using ${ }^{13} \mathrm{C}$ chemical shifts. The results were supported by energy calculations, ${ }^{1} J_{\mathrm{CH}}$ and ${ }^{3} J_{\mathrm{HH}}$ measurements. The correlations and ${ }^{3} J_{\mathrm{HH}}$ measurements for isomenthol indicate conformational averaging impeding the determination of the isopropyl group rotamer. For neoisomenthol, MD simulations showed two chair conformations. However, in contrast to calculated energies and correlations between theoretical and experimental ${ }^{13} \mathrm{C}$ chemical shifts, the measured ${ }^{3} J_{\mathrm{H} 3 \mathrm{H} 2}$ coupling of $6.3 \mathrm{~Hz}$ indicates an equally populated equilibrium of both conformers.
\end{abstract}

(C) 2007 Elsevier B.V. All rights reserved.

Keywords: ${ }^{13} \mathrm{C}$ chemical shift; Menthol; Neomenthol; Isomenthol; Neoisomenthol; DFT; Conformation

\section{Introduction}

Menthol (Fig. 1a) is the major constituent of the essential oil of the Labiaceae (peppermint: Mentha x piperita and spearmint: Mentha spicata) and is used industrially. The determination of menthol in the natural mixture with its four diastereomers isomenthol, neomenthol, and neoisomenthol (Fig. 1b, c, and d) can be done chromatographically or using NMR spectroscopy. In the presence of isomeric forms the high resolution of ${ }^{13} \mathrm{C}$ NMR is advantageous compared to proton NMR. For a reliable assignment the possibility of a mixture of conformers has to be taken into account which has been partially done in the past for some natural products [1-5]. A simulation using the Sybyl force field [6] generated conformers of the men-

\footnotetext{
* Corresponding author. Tel.: +49 551201 2215; fax: +495512012202. E-mail address: urei@nmr.mpibpc.mpg.de (U.M. Reinscheid).
}

thol isomers and tried to correlate structural with organoleptic parameters [7]. Additionally, the equilibrium between menthone and isomenthone was calculated using the DFT approach [8]. Conflicting results concerning the ${ }^{13} \mathrm{C}$ resonances of the menthol isomers $[9,10]$ prompted us to evaluate the conformations of the series of menthol diastereomers using a combined NMR-DFT approach.

\section{Experimental}

\subsection{Computational}

The four isomeric compounds menthol, neomenthol, isomenthol, and neoisomenthol were built using DISCOVER in the InsightII program package (Accelrys ${ }^{\mathrm{TM}}$, [11]). A CVFF force field was chosen. The series of enantiomers starting from $(+)$ menthol $(1 S, 3 S, 4 R)$ shown in Fig. 1a-d was chosen. A high temperature $\left(600^{\circ} \mathrm{C}\right)$ molecular 
a (+) Menthol $\left(1_{\mathrm{eq}} 3_{\mathrm{eq}} 4_{\mathrm{eq}}\right)$

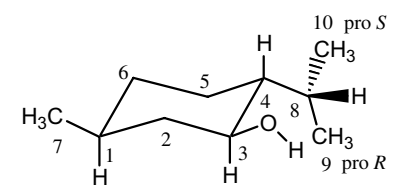

b (+)Neomenthol $\left(1_{\mathrm{eq}} 3_{\mathrm{ax}} 4_{\mathrm{eq}}\right)$

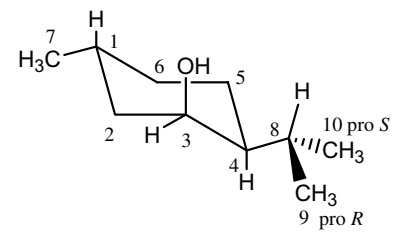

d (+)Neoisomenthol $\left(1_{\mathrm{ax}} 3_{\mathrm{ax}} 4_{\mathrm{eq}}\right)$

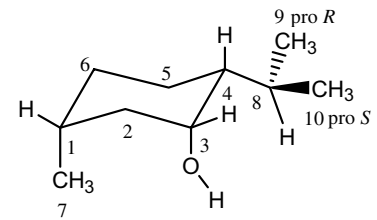

Fig. 1. (a-e) Menthol and the diastereomers neomenthol, isomenthol, and neoisomenthol.

dynamic/minimization simulation was performed and the resulting energy minimized structures were used as starting structures for Gaussian $^{\mathrm{TM}}$ calculations [12]. Geometry optimization, energy calculations and ${ }^{13} \mathrm{C}$ chemical shift calculations were done using B3LYP and a 6-31G(d,p) basis set. The chemical shifts were calibrated with calculated values for TMS $\left(\delta_{\mathrm{C}}=188.85\right)$. Correlation coefficients and standard deviations (SD) of the fits between calculated and experimental data were obtained using Origin ${ }^{\mathrm{TM}}$.

\section{2. $N M R$ spectroscopy}

A solution of $(+)$ menthol $(50 \mathrm{mM})$ in DMSO- $d_{6}$, and solutions of all menthol diastereomers in $\mathrm{CDCl}_{3}(50 \mathrm{mM})$ were measured at $298 \mathrm{~K}$. 1D proton, ${ }^{1} \mathrm{H},{ }^{1} \mathrm{H}-\mathrm{COSY}$ $\left(4 \mathrm{~K} \times 1 \mathrm{~K}, 8\right.$ scans) and ${ }^{1} \mathrm{H},{ }^{13} \mathrm{C}$-HSQC spectra $(4 \mathrm{~K} \times$ $1 \mathrm{~K}, 16$ scans) were recorded with a $400 \mathrm{MHz}$ Bruker Avance spectrometer.

\section{Results and discussion}

In cyclohexane derivatives such as the menthol diastereomers a chair conformation is the dominating conformation (Fig. 1a-e). The position of the three substituents is designated by a shorthand notation. In order to avoid misassignments, we introduce the clear $\operatorname{pro} R / \operatorname{pro} S$ nomenclature for the methyl groups of the isopropyl substituent.

In the first step of our conformational analysis a direct comparison of the measured ${ }^{13} \mathrm{C}$ chemical shifts of menthol
Table 1

${ }^{13} \mathrm{C}$ chemical shifts of menthol

\begin{tabular}{llll}
\hline Numbering & $\begin{array}{l}\text { Senda and } \\
\text { Imaizumi }[10]\left(\mathrm{CDCl}_{3}\right)\end{array}$ & $\begin{array}{l}\text { This study } \\
\left(\mathrm{DMSO}-d_{6}\right)\end{array}$ & $\begin{array}{l}\text { Sassa et al. } \\
{[9]\left(\mathrm{CDCl}_{3}\right)}\end{array}$ \\
\hline C-1 & 32.20 & 32.08 & 31.60 \\
C-2 & 45.90 & 45.94 & 45.10 \\
C-3 & 71.20 & 70.24 & 71.60 \\
C-4 & 50.70 & 50.40 & 30.20 \\
C-5 & 23.80 & 23.64 & 23.10 \\
C-6 & 35.30 & 35.20 & 34.50 \\
C-7 & 22.60 & 23.05 & 22.20 \\
C-8 & 26.10 & 25.80 & 25.90 \\
C-9 & 16.30 & 16.80 & 16.10 \\
C-10 & 21.30 & 21.80 & 21.00 \\
\hline
\end{tabular}

(Table 1) revealed that the natural product isolated by Sassa et al. [9] should not be regarded as menthol. The isolated compound tentatively assigned as menthol by Sassa et al. [9] neither fits to the experimental and calculated chemical shifts of all four menthol isomers nor to the calculated chemical shifts of three positional isomers (same numbering shown in Fig. 1a; isomer I: 1-OH, 4-isopropyl, 6-methyl; isomer II: 1-methyl, 2-OH, 4-isopropyl; isomer III: 4-isopropyl, 5-methyl, 6-OH, data not shown). This inconsistency could be traced back to a typing error [13].

Only minor variations were found between the ${ }^{13} \mathrm{C}$ chemical shifts of menthol in DMSO- $d_{6}$ and the results of Senda and Imaizumi [10] obtained in $\mathrm{CDCl}_{3}$ (Table 1, Fig. 2).

The correct assignment of C-9 and C-10 was accomplished by the DFT calculations of ${ }^{13} \mathrm{C}$ chemical shifts and can be rationalized by the $\gamma$-gauche effect [14] of C-9 in the dominating rotamer. The correlation coefficient of 0.999 and the standard deviation of 0.27 illustrate variation due to experimental conditions (Fig. 2). A nearly perfect linear fit indicates that solvent effects $\left(\mathrm{CDCl}_{3}\right.$ or DMSO$d_{6}$ ) are not important, and can be disregarded in this case.

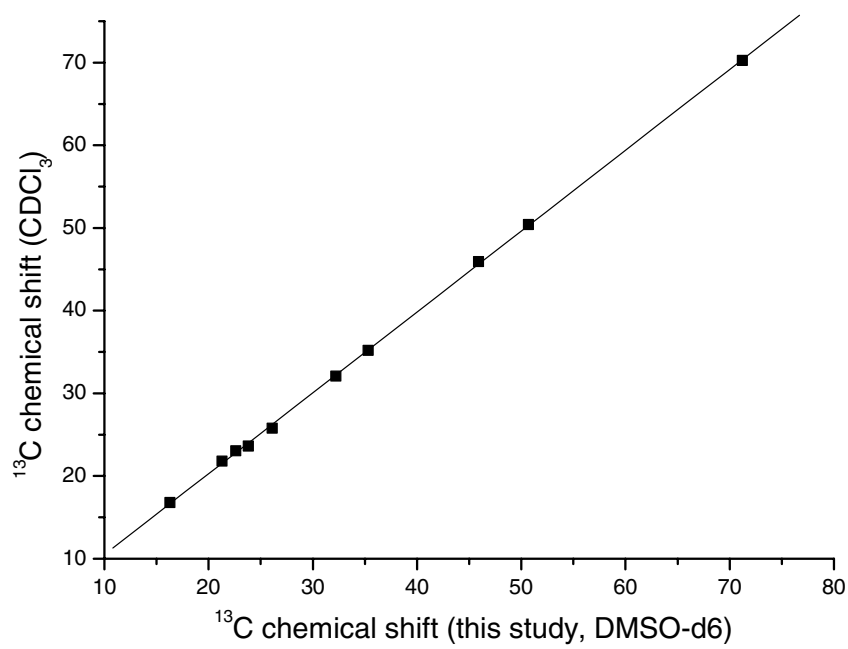

Fig. 2. Fit between ${ }^{13} \mathrm{C}$ experimental values of menthol in two solvents (Senda and Imaizumi [10]: $\mathrm{CDCl}_{3}$; this study: DMSO- $d_{6}$ ). 
The dominating chair of neoisomenthol was predicted to bear the isopropyl group in the axial position (Fig. 1e) [10]. The high-field shift of C-1 compared to menthol would then be explained by a $\gamma$-effect [14] due to the axial positions of the $\mathrm{OH}$-group and the methyl group in the minor $1_{\mathrm{ax}} 3_{\mathrm{ax}} 4_{\mathrm{eq}}$ conformer (Fig. 1d). To evaluate the correct chair conformer of neoisomenthol the structure of Fig. 1e, $\left(1_{\mathrm{eq}} 3_{\mathrm{eq}}\right.$ $4_{\mathrm{ax}}$ ) was obtained by a MD simulation and the ${ }^{13} \mathrm{C}$ chemical shifts were calculated. The best fit was obtained for the $+79.9^{\circ}$ rotamer of the isopropyl group with a correlation coefficient of 0.9811 and a standard deviation of 3.17. This conformer was $1.76 \mathrm{kcal} / \mathrm{mol}$ higher in energy compared to the conformer of Fig. 1d. However, the experimental value of $6.3 \mathrm{~Hz}$ for the ${ }^{3} J_{\mathrm{H} 2 \mathrm{H} 3}$ coupling indicates conformational averaging between the two chair conformers (calculated values: ${ }^{3} J_{\mathrm{H} 2 \mathrm{axH} 3 \mathrm{ax}}=10.1 \mathrm{~Hz}$ of Fig. $1 \mathrm{e}$ and ${ }^{3} J_{\mathrm{H} 2 \mathrm{axH} 3 \mathrm{eq}}=2.67 \mathrm{~Hz}$ of Fig. 1d). The conflicting theoretical results might be explained by the exclusion of solvent effects in the calculations. In 3-substituted cyclohexanols hydrogen bonds were found to stabilize conformers depending on the temperature and this stabilization is not adequately modeled in our calculations [15].

MD simulations in DISCOVER (Accelrys ${ }^{\mathrm{TM}}$ ) revealed different conformations for the four menthol isomers. For isomenthol and neoisomenthol two different chairs were found. The conformers of the other isomers differed only in the dihedral angle of the isopropyl group. This is in agreement with the ${ }^{3} J_{\mathrm{HH}}$ couplings measured in this work $\left({ }^{3} J_{\mathrm{H} 4, \mathrm{H} 8}\right.$ : menthol $(2.5 \mathrm{~Hz})$, neomenthol $(9.2 \mathrm{~Hz})$, isomenthol $(5.5 \mathrm{~Hz})$. The last value indicates conformational averaging and could be explained by the existence of a conformer with an axial isopropyl group [16]. The ${ }^{3} J_{\mathrm{H} 4, \mathrm{H} 8}$ coupling for neoisomenthol could not be determined due to overlapping resonances.

We next studied the dependence of the ${ }^{13} \mathrm{C}$ chemical shifts on the dihedral angle of the isopropyl group. The resulting fits between calculated and experimental ${ }^{13} \mathrm{C}$ chemical shifts of menthol are shown in Fig. 3a-c. The experimental and corrected values were taken from Senda and Imaizumi [10]. The statistical values are shown in
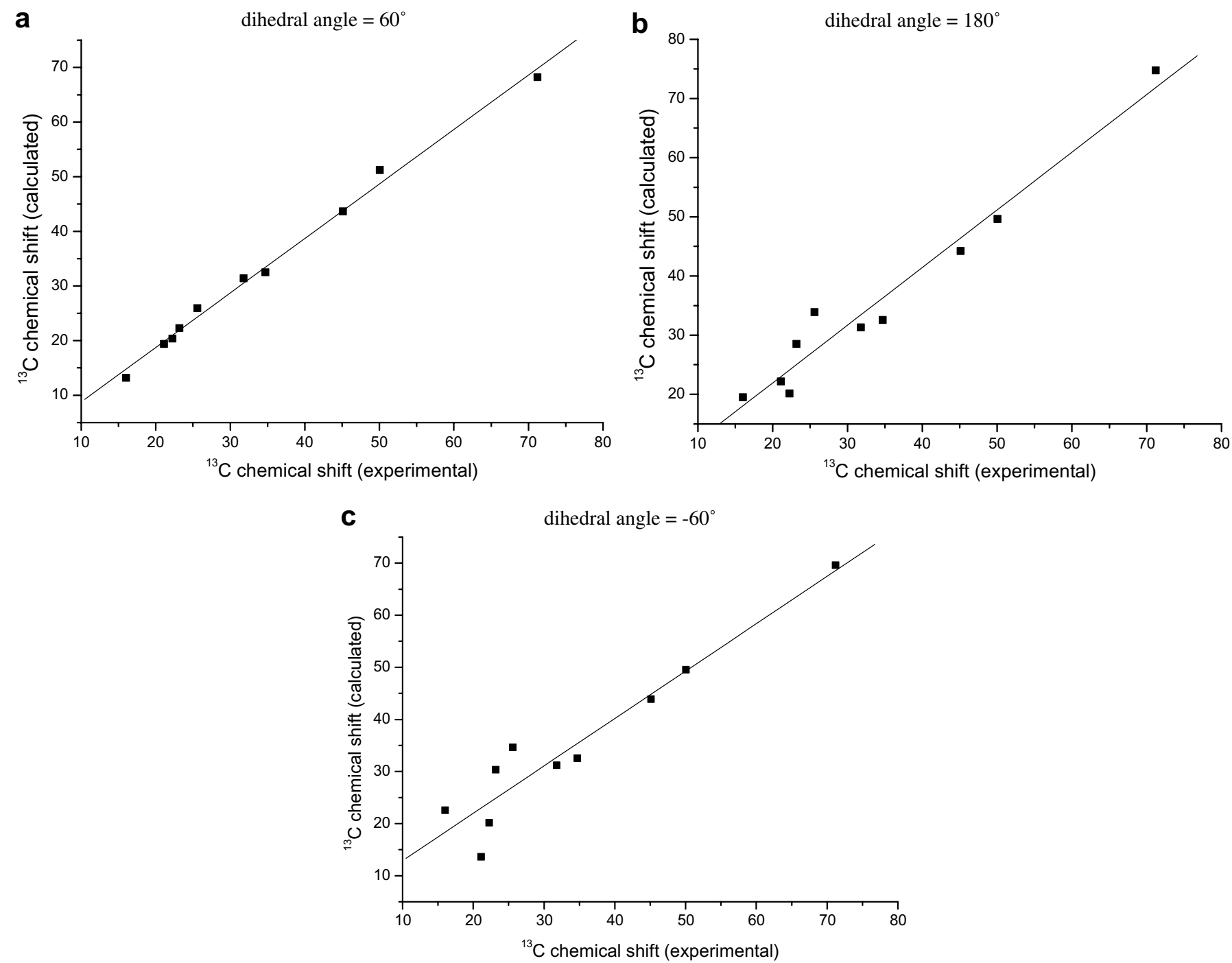

Fig. 3. (a-c) Fits between experimental and calculated ${ }^{13} \mathrm{C}$ chemical shifts for menthol conformers with different dihedral angles of the isopropyl group (H8-C8-C4-H4). 
Table 2

Correlation coefficients and standard deviation (in brackets) of the linear fits between experimental and calculated ${ }^{13} \mathrm{C}$ chemical shifts of the four diastereomeric menthols at different $\mathrm{H} 8-\mathrm{C} 8-\mathrm{C} 4-\mathrm{H} 4$ dihedral angles (dominating conformers are in bold)

\begin{tabular}{llll}
\hline Isomer/dihedral angle & $60^{\circ \mathrm{a}}$ & $180^{\circ \mathrm{b}}$ & $-60^{\circ \mathrm{c}}$ \\
\hline Menthol (Fig. 1a) & $\mathbf{0 . 9 9 6 9 ( 1 . 4 2 )}$ & $0.9788(3.67)$ & $0.9524(5.24)$ \\
Neomenthol (Fig. 1b) & $0.9817(3.33)$ & $\mathbf{0 . 9 9 4 3 ( 1 . 8 5 )}$ & $0.9814(3.81)$ \\
Isomenthol (Fig. 1c) & $0.9752(4.32)$ & $0.9824(3.68)$ & $0.9777(3.66)$ \\
Neoisomenthol (Fig. 1d) & $0.9825(3.47)$ & $0.9935(1.86)$ & $0.9833(3.01)$ \\
\hline
\end{tabular}

${ }^{a}$ Optimized values for menthol, neomenthol, isomenthol, and neoisomenthol: $+68.4^{\circ} \%+55.0^{\circ} /+68.2^{\circ} /+74.4^{\circ}$

b $-174.0^{\circ} /+172.5^{\circ} \%+163.4^{\circ} /-174.7^{\circ}$.

c $-77.9^{\circ} \%-75.4^{\circ} \%-78.4^{\circ} \%-54.8^{\circ}$.

Table 2. The best fit was obtained with a dihedral angle of $+68.4^{\circ}$ in agreement with a recently obtained crystal structure for (-)menthol [17].

\section{a}

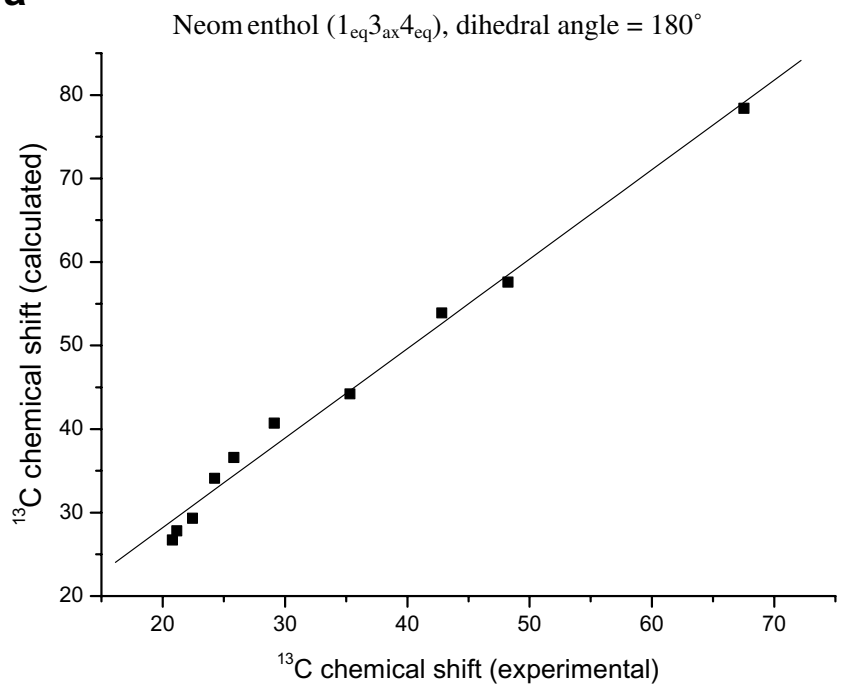

Additionally, we were able to differentiate between the two methyl groups of the isopropyl substituent (pro $R$ and proS, Fig. 1a). The exchange of pro $R$ and pro $S$ carbon assignments in the dominating $+68.4^{\circ}$ conformation led to a worse fit between experimental and calculated values and enabled the assignment of the methyl groups of menthol (correct assignment: correlation coefficient: 0.9969/ $\mathrm{SD}=1.42$, exchanged assignment: correlation coefficient: $0.9846 / \mathrm{SD}=3.15$ ). No measurements of residual dipolar couplings in orienting media [18] were needed for this determination.

The performance of this approach was tested by fitting the experimental values of neomenthol, isomenthol, and neoisomenthol with calculated values of the low energy conformers obtained by simulations with DISCOVER (Fig. 4a-c, Table 2). In contrast to the energetic data (Table 3), the best fit for isomenthol was obtained with
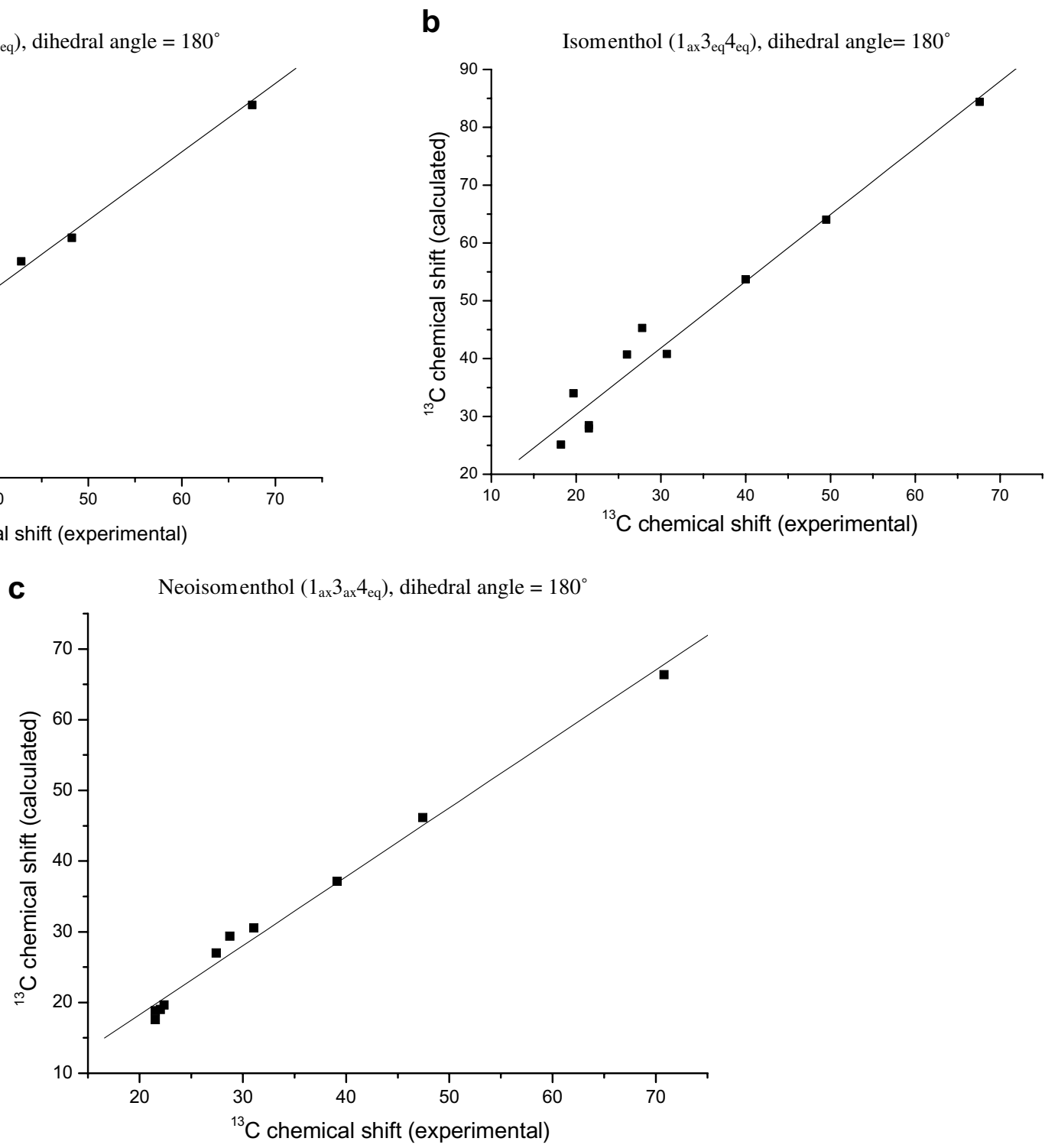

Fig. 4. (a-c) Fits to experimental data of the conformers of neomenthol, isomenthol, and neoisomenthol (isopropyl dihedral angle: H8-C8-C4-H4). 
Table 3

Energy differences in $\mathrm{kcal} / \mathrm{mol}$ of the four diastereomeric menthols at different $\mathrm{H} 8-\mathrm{C} 8-\mathrm{C} 4-\mathrm{H} 4$ dihedral angles

\begin{tabular}{llll}
\hline Isomer/dihedral angle & $60^{\circ}$ & $180^{\circ}$ & $-60^{\circ}$ \\
\hline Menthol (Fig. 1a) & $0^{\mathrm{a}}$ & 1.82 & 0.56 \\
Neomenthol (Fig. 1b) & 1.03 & $0^{\mathrm{b}}$ & 0.83 \\
Isomenthol (Fig. 1c) & $0^{\mathrm{c}}$ & 1.78 & 0.67 \\
Neoisomenthol (Fig. 1d) & 0.98 & $0^{\mathrm{d}}$ & 1.11 \\
\hline
\end{tabular}

${ }^{\mathrm{a}}$ Basis value set to 0: -468.088633 Hartree.

b -468.087743 Hartree.

c -468.084991 Hartree.

d -468.081991 Hartree.

a dihedral angle of $+163.4^{\circ}$ (Table 2). Since the correlation coefficient is substantially smaller compared with the other isomers, we calculated the Boltzmann average with $76 \%$ of the $+68.2^{\circ}$ rotamer and $24 \%$ of the $-78.4^{\circ}$ rotamer. However, even for this mixture a poor correlation coefficient of 0.9786 and a SD of 3.93 were obtained. Since the contributions of other conformers can be assumed to be small on energetic grounds (the lowest energy conformer with the isopropyl group in axial position is $1.47 \mathrm{kcal} / \mathrm{mol}$ higher in energy than the basis conformer (Table 3)), the approach is not sufficient to determine the dihedral angle of the isopropyl group of isomenthol.

However, dihedral angles of $180^{\circ}$ determined for the rotamers of neomenthol and neoisomenthol are supported by energetic data (Table 3 ) and measurements of ${ }^{1} J_{\mathrm{CH}}$ couplings (neomenthol: ${ }^{1} J_{\mathrm{C} 8 \mathrm{H} 8}=123.6 \mathrm{~Hz}$; neoisomenthol ${ }^{1} J_{\mathrm{C} 8, \mathrm{H} 8}=123.7 \mathrm{~Hz}$ ). Axial $\mathrm{CH}$ groups have smaller ${ }^{1} J$ couplings in cyclohexanes [19] due to the $\sigma_{\mathrm{C}-\mathrm{H}} \rightarrow \sigma^{*}{ }_{\mathrm{C}-\mathrm{H}}$ delocalization which is pronounced for the anti arrangement [20].

\section{Conclusions}

In this study, the dominating conformers of menthol and neomenthol were identified based on the comparison between experimental and calculated ${ }^{13} \mathrm{C}$ chemical shifts. The determinations of the rotamers of the isopropyl group based on ${ }^{13} \mathrm{C}$ chemical shift correlations were additionally supported by thermochemical data. Calculated and exper- imental data for isomenthol and neoisomenthol indicate conformational averaging which excludes a simple approach using solely calculated ${ }^{13} \mathrm{C}$ chemical shifts for the conformational analysis. However, the approach helped to identify assignment problems in a recently isolated natural product.

\section{Acknowledgements}

We are grateful for the support of Prof. C. Griesinger, Prof. M. Keusgen (Marburg), and Dr. Panten (Symrise $\mathrm{GmbH}$, Holzminden).

\section{References}

[1] E. Kolehmainen, K. Laihia, R. Laatikainen, J. Vepsäläinen, M. Niemitz, R. Suontamo, Magn. Reson. Chem. 35 (1997) 463.

[2] K.-Y. Kim, S.-G. Lee, Magn. Reson. Chem. 35 (1997) 451.

[3] J.M. Torres-Valencia, M. Meléndez-Rodríguez, R. Álvarez-García, C.M. Cerda-García-Rojas, P. Joseph-Nathan, Magn. Reson. Chem. 42 (2004) 898.

[4] G. Barone, D. Duca, A. Silvestri, L. Gomez-Paloma, R. Riccio, G. Bifulco, Chem. Eur. J. 8 (2002) 3240.

[5] G. Barone, L. Gomez-Paloma, D. Duca, A. Silvestri, R. Riccio, G. Bifulco, Chem. Eur. J. 8 (2002) 3233.

[6] M. Clark, R.D. Cramer III, N. Van Opdenbosch, J. Comp. Chem. 10 (1989) 982.

[7] M. Chastrette, E. Rallet, Flavour Frag. J. 13 (1998) 5.

[8] W.B. Smith, C. Amezcua, Magn. Reson. Chem. 36 (1998) S3.

[9] T. Sassa, H. Kenmoku, M. Sato, T. Murayama, N. Kato, Biosci. Biotechnol. Biochem. 67 (2003) 475.

[10] Y. Senda, S. Imaizumi, Tetrahedron 31 (1975) 2905.

[11] P. Dauber-Osguthorpe, V.A. Roberts, D.J. Osguthorpe, J. Wolff, M. Genest, A.T. Hagler, Proteins Struct. Funct. Genet. 4 (1988) 31.

[12] M.J. Frisch et al., Gaussian 03, Inc., Pittsburgh, PA, 2003.

[13] T. Sassa, personal communication.

[14] H. Günther, NMR Spectroscopy: Basic Principles, Concepts, and Applications in Chemistry, Wiley, Chichester, 1998.

[15] P.R. de Oliveira, L. Tasic, S.A. Rocco, R. Rittner, Magn. Reson. Chem. 44 (2006) 790.

[16] T. Egawa, M. Sakamoto, H. Takeuchi, S. Konaka, J. Phys. Chem. A 107 (2003) 2757.

[17] P. Bombicz, J. Buschmann, P. Luger, N.X. Dung, C.B. Nam, Z. Kristallogr. 214 (1999) 420.

[18] L. Verdier, P. Sakhaii, M. Zweckstetter, C. Griesinger, J. Magn. Reson. 163 (2003) 353.

[19] G. Cuevas, E. Juaristi, J. Am. Chem. Soc. 124 (2002) 13088.

[20] L. Goodman, V. Pophristic, Nature 411 (2001) 565. 